\title{
Rehospitalization in Schizophrenia: Socio Demographic and Clinical Correlates
}

\author{
Parikh MN ${ }^{1}$, Parikh NC ${ }^{2}$, Patel PR $^{3}$ \\ ${ }^{1}$ Dr Minakshi N Parikh, Professor, Department of Psychiatry, BJ Medical College, Civil Hospital Asarwa, 380016, ${ }^{2}$ Dr \\ Nimesh C Parikh Associate Professor, Department of Psychiatry, V.S. General Hospital \& Smt. N.H.L. Municipal Medical \\ College, Ellisbridge, Ahmedabad, 380006 , ${ }^{3}$ Dr Poorav R Patel, Resident Doctor, Department of Psychiatry, BJ Medical \\ College, Civil Hospital, Asarwa, 380016. India
}

Address for correspondence: Dr Minakshi N Parikh, Email id: drminakshiparikh@gmail.com

\section{Introduction:}

Rehospitalisation is an important research tool with two major utility aspects. It is a reliable and valid measure for assessing the course of schizophrenia and a measure of hospital effectiveness. Objectives: The study aimed at finding out the rate of rehospitalization and comparing the various socio-demographic and clinical correlates of rehospitalization in schizophrenia and the reason for rehospitalization amongst first admissions and rehospitalizations. Material and Method: It was a cross sectional study, using DSM - 4 and a specially designed semi structured proforma, carried out in 50 consecutive indoor patients of schizophrenia who were grouped into two: first admissions and rehospitalization. These two groups were compared regarding socio-demographic and clinical variables using the SPSS version 20 for probability. Results: A substantial $54 \%$ of the total patients were rehospitalisation cases. $85.19 \%$ of the readmitted group had illness duration of more than 2 years. Non-medical treatment sought by patient's relatives before hospitalization was $73.91 \%$ among the first admission as compared to only $18.51 \%(\mathrm{P}<0.05)$ of rehospitalization group. Rehospitalizations were positively and significantly correlated with older age, low educational level $(\mathrm{p}<0.05)$ and low income level. Conclusion: We observed that de novo cases wasted significantly more time before coming for treatment which stresses the need for psychoeducation of schizophrenia caretakers. Our study also found that economic status and education level significantly affect rehospitalisation. This highlights importance of socioeconomic factors in the prediction of rehospitalisation along with clinical correlates.

Key words: Rehospitalization, socio-demographic variables, clinical variables, Schizoprenia

\section{Introduction}

The phenomenon of rehospitalization of schizophrenic patient has been a matter of increasing concern ever since the concepts of 'De-institutionalisation' and 'Community care' of these patients have been emphasised. Rehospitalization statistics are the mainstay of assessing the degree to which current hospital practises are achieving the goals that have been set.

Other indicators such as median length of hospital stay, comparing patient pathology at admission and discharge, or determining the extent to which discharged patients find employment in the community have been used, but rehospitalization statistics are more widely used and find greater acceptance than any other indicator because of certainty of their methodological characteristics.

They are easy to obtain, are highly reliable (A patient was formerly admitted or was not) and are very easy to quantify. These assets have led rehospitalization statistics

Manuscript received: $03^{\text {rd }}$ Mar 2014

Reviewed: $05^{\text {th }}$ Mar 2014

Author Corrected: 13 ${ }^{\text {th }}$ Mar 2014

Accepted for Publication: $07^{\text {st }}$ Apr 2014 to become the indicator par excellence of hospital effectiveness and the central criterion of usual definition of relapse. There have been hundreds of studies of relapse using rehospitalization as central criterion. As reviewed by IRH Falloon [1], 40\% of studies (Johnson ('75), del Guidice ('75), Linn ('79), Matthew ('79), Abuzzahab \& Zimmerman ('80)) used "Hospital Rehospitalizations" as the sole criterion. These studies have used hospital rehospitalization in association with specific or nonspecific clinical deterioration or social impairment. Lin $\mathrm{CH}$ et al assessed the correlation between different treatment modalities and rehospitalisation rates and observed that there was no significant difference in rates of rehospitalisation between patients treated with typical anti-psychotics or clozapine or risperidone [2].

Kobayashi et al in a retrospective study of 460 discharged patients of schizophrenia showed significant positive correlation between smoking and rehospitalizations in schizophrenia [3]. In the perspective of increasing importance of social and community psychiatry recently, 
the present study is an attempt to provide an impetus for further research efforts and clinical interests in rehospitalizations of schizophrenic patient. We have conducted this study to find out the prevalence of rehospitalization among schizophrenic patients \& compare the sociodemographic variables, clinical variables, non-medical treatment-seeking and reasons for admission in first hospitalization vs rehospitalization.

\section{Materials and method}

The study was conducted in the psychiatry ward of a general hospital attached to a teaching institute. It has acute admission unit having 28 beds and no long stay or rehabilitation bed. Patients admitted to the in-patient facility were screened. 50 consecutive adult patients willing to participate in the study, satisfying DSM IV TR criteria for schizophrenia, as diagnosed by two senior psychiatrists were included in the study after taking informed consent. Patients with co-morbidity in the form of epilepsy, mental retardation, major physical illness or substance use disorder were excluded from the study. Each patient was interviewed in detail and data was collected with the help of a semi structured proforma. The relevant socio demographic variables, clinical features including family history of mental illness and nonmedical treatment taken so far were recorded. Details of previous hospitalization and follow up in case of rehospitalization were also assessed. Afterwards, the patients were grouped into First hospitalization and Rehospitalization groups. Rehospitalisation implies patients who had a record of past hospitalization in the same psychiatric department.

All the data was tabulated and these two groups were compared regarding socio demographic and clinical variables using the SPSS version 16 for probability.

\section{Results}

In the present study, out of 50 consecutive schizophrenic patients, 27 patients had been admitted previously to our department, whereas, 23 patients were first admissions. This implies a substantial 54\% of rate of rehospitalization in schizophrenia.

Table 1: Socio-Demographic Correlates of Rehospitalization in Schizophrenia

\begin{tabular}{|c|c|c|c|c|c|}
\hline \multicolumn{2}{|c|}{ Variables } & $\begin{array}{l}\text { Total } \\
\text { Number } \\
\mathrm{N}=50\end{array}$ & $\begin{array}{c}\text { First } \\
\text { hospitalization } \\
\mathrm{N}=23\end{array}$ & $\begin{array}{c}\text { Rehospitalization } \\
\qquad \mathrm{N}=27\end{array}$ & $\mathrm{P}$ \\
\hline \multirow[t]{2}{*}{ Age in Years } & $15-30$ & 25 & 12 & 13 & \multirow{2}{*}{$\begin{array}{c}\text { N.S } \\
X^{2}=0.81 \\
P=0.777\end{array}$} \\
\hline & $>30$ & 25 & 11 & 14 & \\
\hline \multirow[t]{2}{*}{ Sex } & Male & 30 & 15 & 15 & \multirow{2}{*}{$\begin{array}{c}\mathrm{X}^{2}=0.483 \\
\mathrm{P}=0.487\end{array}$} \\
\hline & Female & 20 & 8 & 12 & \\
\hline \multirow[t]{2}{*}{ Religion } & Hindu & 39 & 19 & 20 & \multirow{2}{*}{$\begin{array}{c}\mathrm{X}^{2}=0.527 \\
\mathrm{P}=0.468\end{array}$} \\
\hline & Others & 11 & 4 & 7 & \\
\hline \multirow[t]{2}{*}{ Education } & $4^{\text {th }}$ & 23 & 6 & 17 & \multirow{2}{*}{$\begin{array}{c}\text { Significant } \\
\mathrm{P}=0.009 \\
\mathrm{X}^{2}=6.799\end{array}$} \\
\hline & $\geq 5^{\text {th }}$ & 27 & 17 & 10 & \\
\hline \multirow[t]{4}{*}{ Occupation } & Unemployed & 13 & 4 & 9 & \multirow{4}{*}{$\begin{array}{c}X^{2}=4.660 \\
P=0.198\end{array}$} \\
\hline & Unskilled & 25 & 11 & 14 & \\
\hline & Semiskilled & 6 & 3 & 3 & \\
\hline & $\begin{array}{c}\text { Clerical/ } \\
\text { professional }\end{array}$ & 6 & 5 & 1 & \\
\hline \multirow{3}{*}{$\begin{array}{c}\text { Income } \\
\text { Rs./month }\end{array}$} & Upto 3000 & 18 & 5 & 13 & \multirow{3}{*}{$\begin{array}{c}\mathrm{X}^{2}=3.760 \\
\mathrm{P}=0.050 \\
\text { significant }\end{array}$} \\
\hline & $>3000$ & 32 & 18 & 14 & \\
\hline & & & & & \\
\hline \multirow[t]{2}{*}{ Domicile } & Urban & 35 & 17 & 18 & \multirow{2}{*}{$\begin{array}{c}\mathrm{X}^{2}=0.311 \\
\mathrm{P}=0.577\end{array}$} \\
\hline & Rural & 15 & 6 & 9 & \\
\hline \multirow{3}{*}{$\begin{array}{l}\text { Distance From } \\
\text { Hospital In km. }\end{array}$} & $0-10$ & 30 & 15 & 15 & \multirow{3}{*}{$\begin{array}{c}\mathrm{X}^{2}=0.517 \\
\mathrm{P}=0.772\end{array}$} \\
\hline & $11-50$ & 8 & 3 & 5 & \\
\hline & $>50$ & 12 & 5 & 7 & \\
\hline \multirow[t]{2}{*}{ Marital Status } & Married & 31 & 13 & 18 & \multirow{2}{*}{$\begin{array}{c}X^{2}=0.543 \\
P=0.467\end{array}$} \\
\hline & Single & 19 & 10 & 9 & \\
\hline \multirow{2}{*}{$\begin{array}{l}\text { Family } \\
\text { Structure }\end{array}$} & Nuclear & 28 & 12 & 16 & \multirow{2}{*}{$\begin{array}{c}X^{2}=0.253 \\
P=0.615\end{array}$} \\
\hline & Joint & 22 & 11 & 11 & \\
\hline
\end{tabular}


Although no statistically significant difference was found amongst both the groups as regards to the socio-demographic factors like gender, religion, occupation, domicile, distance from the hospital and family structure, we found a statistically significant correlation $(\mathrm{p}<0.05)$ between lower educational level as well as lower income and readmission.

The present study also found considerable positive correlation (though not statistically significant, P $>0.05$ ) between rehospitalization and older age.

Table 2: Number of previous admissions in the rehospitalizations in schizophrenia

\begin{tabular}{|c|c|c|}
\hline Number of Previous hospitalization. & $\begin{array}{c}\text { Total Number } \\
\mathrm{N}=27\end{array}$ & Percentage \\
\hline 1 & 12 & $44.44 \%$ \\
\hline 2 & 8 & $29.63 \%$ \\
\hline 3 or more & 7 & $25.93 \%$ \\
\hline
\end{tabular}

As depicted in the table, in our study, $44.44 \%$ of the patients had had one previous admission, $29.63 \%$ had 2 admissions in the past and $25.93 \%$ had 3 or more previous admissions

Table 3- Clinical Correlates of Rehospitalization in Schizophrenia (1)

\begin{tabular}{|c|c|c|c|c|c|}
\hline & $\begin{array}{l}\text { Total number } \\
\qquad \mathrm{N}=50\end{array}$ & Firs & lization. & & $\begin{array}{l}\text { ization } \\
7\end{array}$ \\
\hline \multicolumn{2}{|l|}{ Family history: } & \multicolumn{4}{|c|}{$\mathrm{X}^{2}=0.012 \mathrm{P}=0.914$ Not Significant $\mathrm{P}>0.5$} \\
\hline 1) Positive & 17 & \multicolumn{2}{|c|}{8} & \multicolumn{2}{|c|}{9} \\
\hline 2) Negative & 33 & \multicolumn{2}{|c|}{15} & \multicolumn{2}{|c|}{18} \\
\hline \multicolumn{2}{|c|}{ Precipitating factors: } & \multicolumn{4}{|c|}{$\mathrm{X}^{2}=2.715 \mathrm{P}=0.091$, Not Significant $\mathrm{P}<1$} \\
\hline 1) Present & 12 & 8 & $34.78 \%$ & 4 & $14.81 \%$ \\
\hline 2) Absent & 38 & 15 & $65.22 \%$ & 23 & $85.19 \%$ \\
\hline \multicolumn{2}{|c|}{ Duration of illness: } & \multicolumn{4}{|c|}{$\mathrm{X}^{2}=6.068 \mathrm{P}=0.048$, Significant } \\
\hline 1) $0.5-2$ & 14 & 10 & $43.57 \%$ & 4 & $14.81 \%$ \\
\hline 2) $2-5$ & 18 & 8 & & 10 & \\
\hline 3) More than 5 & 18 & 5 & $56.53 \%$ & 13 & $85.19 \%$ \\
\hline
\end{tabular}

As apparent in table II, in the present study no significant correlation was found between rehospitalization and family history of mental illness.

Although not reaching statistically significant proportion it is notable that $34.78 \%$ of first admissions had experienced a significant life event in the 3 weeks prior to onset of illness compared to only $14.81 \%$ of readmitted patients had done so.

Statistically significant correlation $(\mathrm{p}<0.05)$ was found between chronicity and rehospitalizations. $43.47 \%$ of the first admission has duration of less than 2 years as compared to only $14.81 \%$ of the readmitted patients and $56.53 \%$ of the first admission had more than 2 years duration as compared to $85.19 \%$ of the readmitted patients. 
Table 4: Clinical Correlates of Rehospitalization in Schizophrenia (2)

\begin{tabular}{|c|c|c|c|c|c|c|}
\hline & & $\begin{array}{c}\text { Total Number } \\
\mathrm{N}=50\end{array}$ & \multicolumn{2}{|c|}{$\begin{array}{c}\text { First Admission } \\
\mathrm{N}=23\end{array}$} & \multicolumn{2}{|c|}{$\begin{array}{c}\text { Rehospitalization } \\
\mathrm{N}=27\end{array}$} \\
\hline \multicolumn{3}{|c|}{ Duration before Hospitalization: } & \multicolumn{4}{|c|}{$\mathrm{X}^{2}=7.178 \mathrm{P}=0.028$, Significant } \\
\hline \multicolumn{2}{|l|}{ Up to 7 Days } & \multirow{2}{*}{$\begin{array}{l}17 \\
20\end{array}$} & 5 & $21.74 \%$ & 12 & $44.4 \%$ \\
\hline \multicolumn{2}{|c|}{ 7Days to 1 Month } & & 8 & $34.79 \%$ & 12 & $44.4 \%$ \\
\hline \multicolumn{2}{|c|}{ More than 1 Month } & 13 & 10 & $43.47 \%$ & 3 & $11.11 \%$ \\
\hline \multicolumn{3}{|c|}{ Non-Medical treatment seeking: } & \multicolumn{4}{|c|}{$\mathrm{X}^{2}=15.467, \mathrm{P}=0.000$, Significant } \\
\hline \multicolumn{2}{|l|}{ Taken } & 22 & 17 & $73.91 \%$ & 5 & $18.51 \%$ \\
\hline \multicolumn{2}{|l|}{ Not Taken } & 28 & 6 & $26.09 \%$ & 22 & $81.49 \%$ \\
\hline \multicolumn{3}{|c|}{ Duration of Hospital stay: } & \multicolumn{4}{|c|}{$\mathrm{X}^{2}=1.810, \mathrm{P}=0.179$, Not Significant } \\
\hline \multicolumn{2}{|l|}{ Up to 14 days } & 21 & 12 & $52.18 \%$ & 9 & $33.33 \%$ \\
\hline \multicolumn{2}{|c|}{ More than 14 days } & 29 & 11 & $47.82 \%$ & 18 & $66.67 \%$ \\
\hline \multicolumn{3}{|c|}{ Reasons for admission: } & \multicolumn{4}{|c|}{$\mathrm{X}^{2}=7.423, \mathrm{P}=0.060$ not Significant } \\
\hline \multirow[t]{2}{*}{$\begin{array}{l}\text { Acute } \\
\text { exacerbation }\end{array}$} & $\begin{array}{l}\text { Irregular } \\
\text { treatment }\end{array}$ & 37 & \multicolumn{2}{|c|}{15} & \multicolumn{2}{|c|}{22} \\
\hline & $\begin{array}{l}\text { Regular } \\
\text { treatment }\end{array}$ & 5 & \multicolumn{2}{|c|}{1} & \multicolumn{2}{|c|}{4} \\
\hline \multicolumn{2}{|c|}{ For social reasons } & 7 & \multicolumn{2}{|c|}{6} & \multicolumn{2}{|c|}{1} \\
\hline \multicolumn{2}{|c|}{ Others eg. EPS } & 1 & \multicolumn{2}{|c|}{1} & \multicolumn{2}{|c|}{0} \\
\hline
\end{tabular}

In the present study only $11.11 \%$ of readmitted patients sought hospital treatment after one month of the ongoing exacerbation as compared to $43.47 \%$ of the first admission group. This is statistically significant $(p<0.05)$ and suggests a negative correlation between the duration of ongoing exacerbation before admission and the readmitted patients. It indirectly implicates that knowledge of relatives due to previous admission helps them to seek right treatment promptly.

Interestingly, in the present study, it was found that non-medical treatment sought by patient's relative before hospitalization was $73.91 \%$ among the first admission as compared to only $18.51 \%$ of the readmitted patients. This is statistically significant $(\mathrm{p}<0.01)$ and suggests a correlation of rehospitalization with much less frequent non-medical help seeking.

In the present study, $47.82 \%$ of the first admissions had a stay of more than two weeks as compared to $66.67 \%$ of the readmitted group.

As is expected, admission for the management of acute exacerbation of symptoms is the commonest reason for both the groups viz. in $69.56 \%$ of the first admissions and in $96.29 \%$ of the rehospitalizations. But, interestingly, $81.48 \%$ of the readmitted patients were not under the cover of antipsychotic drug when they had an acute exacerbation. Also, the patients admitted for social reasons are mostly from the first admissions group (85.71\%) and very few from the readmitted group $(14.29 \%)$.

\section{Discussion}

In studies all over the world, rehospitalization rates vary from 9 to $71 \%$ [3]. The present finding of $54 \%$ of rehospitalization rate is within the above quoted range. Birley \& Brown [4] reported a rehospitalization rate of $52 \%$; among Indian researchers, Fernandez et al [5] reported rehospitalization rate of $21.64 \%$ in general psychiatric patients, while Gangil et al [6] observes it to be $39.9 \%$ in psychotic patients. As concluded by Fernandez et al [5] methodological reasons account for such a wide variation. In the presence study, we did not find any statistically significant correlation between rehospitalization and socio demographic variables like Sex, Religion, Occupation, Domicile, distance from hospital, Marital Status and Family structure which is in accordance with the findings of previous studies [4, 7] but contrary to the findings of two studies conducted in the US [9] in 2006 and Singapore [10] in 2005 that found that male gender was associated with an increased risk of 20-

Available online at: $\underline{\text { www.ijmrr.in }} 181$ | P a g e 
Research Article

month and one-year rehospitalization rates among acute psychiatric inpatients and schizophrenic patients, respectively. Fernandez et al [5] found significant positive correlation between rehospitalization and the distance of less than $50 \mathrm{~km}$ from the hospital. Study by Malhotra et al [7] reported similar findings except there was a significant correlation between older age group and rehospitalization. The findings of Kulhara et al [8] in 1989 and Marks F.M [12] in 1977 are also in accordance with above findings.

We found statistically significant $(\mathrm{P}<0.05)$ correlation between lower educational as well as lower economic status and rehospitalization in schizophrenia which is different from the findings of Fernandez et al [4] and Kulhara et al [8], who did not report such a correlation. The difference may be accorded to the fact that they conducted their study in general psychiatric patients whereas the present study includes only schizophrenic patients.

The present study also found considerable correlation (though not statistically significant) between rehospitalization and older age. These findings are in accordance with the observation of Malhotra et al [7].The possible explanation for correlation between older age and lower income in rehospitalization in schizophrenic patients may be the fact that the readmitted patients represent the more chronic schizophrenic population who is known to experience the downward social and economic drift.

Coming to Clinical variables in rehospitalization of schizophrenia, studies conducted by Gangil et al [6], Kulhara et al [8],Vaillant [12] reported that there is no significant correlation between rehospitalization in schizophrenia and family history of mental illness. These findings are in accordance with the present study.

Although the higher prevalence of presence of a precipitating event in first admissions as compared to readmissions does not reach a statistically significant proportion, it is in accordance with observation by Leff et.al 13], Birley and Brown [5], Steingberg and Durell [14] who respectively noted that the Proportion of patients experiencing any event in the final three weeks before the illness was very similar in first and rehospitalization and when not under the cover of Antipsychotic drugs and there is a precipitating life-event, the rate of admission in rehospitalization and the control group is similar, but when under cover of antipsychotic drugs, the rate of rehospitalisation is lower.

It is appropriate to mention at this juncture that in our study, 24 out of 27 readmitted patients had discontinued

International Journal of Medical Research and Review antipsychotic at time of exacerbation. So if stoppage of anti-psychotic is considered to be precipitating factor, $88.89 \%$ of readmitted patients had experienced it.

Chronicity of schizophrenic illness is consistently related to rehospitalization. We have made this observation which is in concordance with the findings of many previous studies. They note that more than 5 years duration implies a $98 \%$ chance of relapse, the maximum chances being between the second and the third year [15, 17-19].

Both, the duration of present exacerbation before hospitalization and help of non- medical treatment before admission are issues that are integrally bound to Indian culture where schizophrenic patients' relatives are known to seek non-medical help i.e. faith-healing, before they reach the psychiatrist. Unfortunately, no study done on the subject of rehospitalization in the Indian set up has considered this very sensitive and culture-bound aspect of the ignorance and mis-concepts regarding schizophrenic illness.

We have successfully, tried to bring to light the fact that before first hospitalization the ignorance and misconcepts regarding schizophrenic illness are rampant, whereas in readmitted group they are considerably less. This could be attributed to the direct intervention by the clinician in the form of family therapy as well as rolemodelling offered by other patients and their relatives.

Our findings suggest a longer duration of hospital stay during rehospitalizations which is in accordance with the findings of Malhotra et al [7] in 1982 who concluded that hospital stay of rehospitalizations was longer in general hospital psychiatric unit. Rosenblatt and Mayer [15], Marks [11], contend that rehospitalizations are consistently correlated with short length of hospital stay than previous admissions.

Our study found that acute exacerbation of symptoms is the commonest indication for hospitalisation just as reviewed by Malhotra et al [7] in 1982 the reasons for rehospitalizations are usually acute exacerbation or relapse of symptoms whereas Rosenblatt and Mayer [15] contended that there may be social reasons for rehospitalization too. The difference can be explained by the fact that Malhotra et al [7] conducted their study in general hospital where patients are admitted for acute management only.

In our study, $55.56 \%$ of the patients had had more than one previous admissions which is slightly higher than the result (44\%) of other studies, Behere et al [16] $-22.8 \%$,

Available online at: $\underline{\text { www.ijmrr.in }} 182$ | P a g e 
Research Article

Kulhara et al [8] 35\%, and Marks F.M. [11], which were conducted in general psychiatric patients. As also studied in India by Malhotra et al [7] and Behere et al [16], the percentage of more than one previous admission is 35 and 23 respectively.

In fact, as suggested by Thara et al [17] in their study, in schizophrenic patients, by the end of 5 years, $98 \%$ would experience relapse. The results of this study are in accordance with those of Kulhara et al [8] and Rosenblatt et al [15]. The explanation lies in the natural course of schizophrenic illness, that more chronic patients have naturally had more remission [20]. Rosenblatt and Mayer]15] reviewed all past studies on the subject in 1974 and concluded that the patients were more likely to return if they had a greater number of previous admissions. They summarised that $40 \%$ of rehospitalizations had more than one previous admission [20].

\section{Conclusion}

The wave of deinstitutionalisation and community care has left the onus of schizophrenic patient care onto the shoulders of their relatives. The relatively high rates of rehospitalisation leave a lot to be said about schizophrenia care in general.

On one hand, the advent of newer and more specific medicines is making positive and negative symptom resolution better everyday but on the other hand a lot of stigma and misconcepts about schizophrenia prevail in the community; due to which, especially in developing countries, relatives spend a lot of valuable time in denial and faith healing (non-medical help-seeking).

Giving scientific and pertinent knowledge about schizophrenia to caretakers thereby dispelling their misconcepts and hammering into them the need for regular follow-up management might go a long way towards reducing the rates of drug-default and rehospitalization.

\section{Funding: Nil}

\section{Conflict of interest: Nil}

\section{Permission from IRB: Yes}

\section{References}

1. Falloon IRH, Marshall GN, Boyd J.L., Razani J., Wood-Siverio C.; Relapse in schizophrenia: A review of concept and its definitions- Editorial. Psychological Medicine, 1983, 13,469-77.

International Journal of Medical Research and Review
2. Lin CH, Lin SC, Chen MC, Wang SY; comparison of time to rehospitalisation among schizophrenia patients discharged on typical antipsychotics, clozapine or risperidone. J Chin Med Assoc.2006 Jun; 69(6):264-9.

3. Kobayashi M, Ito H, Okumura Y, Mayahara K, Matsumoto Y, Hirakawa J.; Hospital rehospitalisation in first-time admitted patients with schizophrenia. Int $\mathbf{J}$ Psychiatry Med. 2010; 40(3):247-57.

4. Birley JLT., Brown GW.; Crises and Life Changes Preceding the Onset or Relapse of Acute Schizophrenia: Clinical Aspects. British Journal of Psychiatry, 1970, 116,327-33.

5. Fernandez A, Chaturvedi SK, Beig A, Gopinath PS; Rehospitalization of psychiatric patients in psychiatric hospital : Indian Journal of Psychiatry, 1987, 29(1),85-88.

6. Gangil OP, Adityakumar,Yadav B.S., Jain R.K.; Family history of mental illness as a factor in relapse and non-relapse of discharge functional psychotics. Indian Journal of Psychiatry,1982, 24(1),84-87.

7. Malhotra S, Murthy RS, Verma VK, Ghosh A, Wig NN; Rehospitalization in general hospital psychiatric unitsocio economic and clinical correlates: Indian Journal of Psychiatry ,1982, 24(1),37-4.

8. Kulhara P, Avasthi A, Chandiramani K.; Prognostic variables in schizophrenia : Indian Journal of Psychiatry, 1989, 31(1),51-62.

9. Woo BK, Golshan S, Allen EC, Daly JW, Jeste DV, Sewell DD. Factors associated with frequent admissions to an acute geriatric psychiatric inpatient unit. J. Geriatric Psychiatry Neurology, 2006 ; 19:226-30.

10. Mahendran R, Mythily, Chong SA, Chan YH. Brief communication: factors affecting rehospitalisation in psychiatric patients in Singapore. Int $J$ Soc Psychiatry, 2005;51:101-5

11. Marks FM; The characteristic of psychiatric patient readmitted within a month of discharge. Psychological Medicine, 1977, 7,345-52.

12. Vaillant GE; Prospective prediction of schizophrenic remission:Archives ofGeneralPsychiatry,1964,11,509-518

13. Leff J, Kuipers L., Berkowitz R., Vaughn C., Sturgeon D.; Life events, relative's expressed emotions and maintenance neuroleptics in schizophrenic relapse. Psychological Medicine, 1983, 13,799-806.

Available online at: www.ijmrr.in 183 | P a g e 
14. Steinberg HR, Durell J.; A stressful situation as a precipitant of schizophrenic symptoms: British Journal of Psychiatry, 1968, 114,1097-1105.

15. Rosenblatt A, DSW, Mayer JE.; The Recidivism of mental patients: Review of past studies: American Journal of Orthopsychiatry,1974,44(5),697-706.

16. Behere PB; Tiwari K, Behere M.; Changing diagnosis in Psychiatry: Indian Journal of Psychiatry, 1988, 30(1), 73-77.

17. Thara R, Raman KJ, Srinivasan TN, Rajkumar S, Vijaya Laxmi V.; Study of relapses in schizophrenia using the life table method: Indian Journal of Psychiatry, 1987, 29(3),263-67.
18. Verghese A, Dube KC; Factors associated with course and outcome of schizophrenia : Indian Journal of Psychiatry, 1985, 27. 201-04.

19.Carpenter WT, Bartko JJ, Strauss JS, Hawk AB. Signs and symptoms as predictors of outcome: a report from the International Pilot Study of Schizophrenia. Am J Psychiatry.1978 Aug;135(8):940-4.

20. Ciompi L; The natural history of schizophrenia in the long term: British Journal of Psychiatry, 1980, 136, 413-20.

\section{How to cite this article?}

Parikh MN, Parikh NC, Patel PR. Rehospitalization in Schizophrenia: Socio Demographic and Clinical Correlates. Int J Med Res Rev 2014;2(3):178-184. doi.10.17511/ijmrr.2014.i03.02 